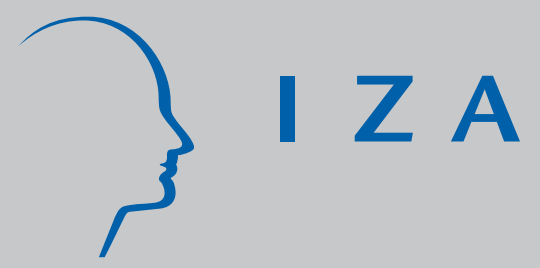

IZA DP No. 1148

Charitable Giving as a Gift Exchange: Evidence from a Field Experiment

Armin Falk

May 2004 


\title{
Charitable Giving as a Gift Exchange: Evidence from a Field Experiment
}

\author{
Armin Falk \\ IZA Bonn, University of Bonn, \\ CEPR and CESifo
}
Discussion Paper No. 1148
May 2004

\author{
IZA \\ P.O. Box 7240 \\ 53072 Bonn \\ Germany \\ Phone: +49-228-3894-0 \\ Fax: +49-228-3894-180 \\ Email: iza@iza.org
}

\begin{abstract}
Any opinions expressed here are those of the author(s) and not those of the institute. Research disseminated by IZA may include views on policy, but the institute itself takes no institutional policy positions.

The Institute for the Study of Labor (IZA) in Bonn is a local and virtual international research center and a place of communication between science, politics and business. IZA is an independent nonprofit company supported by Deutsche Post World Net. The center is associated with the University of Bonn and offers a stimulating research environment through its research networks, research support, and visitors and doctoral programs. IZA engages in (i) original and internationally competitive research in all fields of labor economics, (ii) development of policy concepts, and (iii) dissemination of research results and concepts to the interested public.
\end{abstract}

IZA Discussion Papers often represent preliminary work and are circulated to encourage discussion. Citation of such a paper should account for its provisional character. A revised version may be available on the IZA website (www.iza.org) or directly from the author. 


\section{ABSTRACT}

\section{Charitable Giving as a Gift Exchange: Evidence from a Field Experiment}

This study reports data from a field experiment that was conducted to investigate the relevance of gift-exchange for charitable giving. Roughly 10,000 solicitation letters were sent to potential donors in the experiment. One third of the letters contained no gift, one third contained a small gift and one third contained a large gift. Whether a potential donor received a letter with or without a gift was randomly determined. We observe strong and systematic effects from including gifts. Compared to the no gift condition, the relative frequency of donations increased by 17 percent if a small gift was included and by 75 percent for a large gift. Consequently, including gifts was highly profitable for the charitable organization. The contribution of this paper is twofold: first, it shows that gift-exchange is important for charitable giving, in addition to the warm-glow motive. Second, the paper confirms the economic relevance of reciprocity by using field data. This extends the current body of research on reciprocity, which is almost exclusively confined to laboratory studies.

JEL Classification: C93, D63, H41

Keywords: charitable giving, field experiments, reciprocity

Corresponding author:

Armin Falk

IZA Bonn

P.O. Box 7240

53072 Bonn

Germany

Email: falk@iza.org 


\section{INTRODUCTION}

This study reports data from a field experiment that investigates the relevance of giftexchange for charitable giving. In our study, roughly 10,000 solicitation letters were sent to potential donors. One third of the recipients received the letter without a gift, one third received a small gift and one third received a large gift. This completely exogenous treatment variation created strong and systematic effects: compared to the no gift condition, the relative frequency of donations increased by 17 percent if a small gift was included and by as much as 75 percent for a large one. Similarly the absolute amount of money donated increased substantially if a gift, in particular a large gift, was included. Thus our data provide evidence for the relevance of gift-exchange for charitable giving. Initiating such a gift exchange was highly profitable for the organization.

The contribution of this paper is twofold: first it adds to the understanding of the motives behind charitable giving. The economic importance of investigating theses motives derives from the fact that the amount of donated money is quite substantial in many nations. In the US, for example, almost 70 percent of all households make charitable contributions, exceeding 1 percent of GDP (Andreoni et al. 1996). The motive that has attracted the most attention both in the theoretical and the empirical literature is (impure) altruism or "warm glow", i.e., the internal satisfaction that arises from helping others. Several empirical studies have provided evidence that feelings of warm glow are important determinants in the decision to donate (Andreoni 1995). While the present study confirms the relevance of this motive, it also shows that in addition to warm glow, donors are significantly affected by gift exchange considerations. Second the paper extends the research on reciprocal motivation. Reciprocity means that people are inclined to reward kind actions, e.g., to repay a gift or a favor (for an overview on the empirical literature see Fehr and Gächter 2000). While numerous laboratory studies have confirmed the importance of this motive for human decision making, there is little field evidence for the relevance of reciprocity. Our study provides a step in filling this gap.

Field experiments offer a particularly well suited research tool for investigating the motives behind charitable giving. In contrast with traditional field studies, it is possible to create an exogenous variation in the variables of interest in a field experiment. While this can also be realized in laboratory experiments, field experiments have the additional advantage that people take their actions in their natural environment. In another field 
experiment on charitable giving, List and Lucking-Reiley (2002) demonstrate the behavioral importance of seed money and refund policies. Increasing seed money from 10 percent to 67 percent produced an almost sixfold increase in donations. Likewise, the introduction of a refund policy increased donations by roughly 20 percent. Frey and Meier (2003) study charitable giving to a social fund administered by the University of Zurich. They systematically vary the information about other students' contributions and show that students increase their donations if they believe that others have also donated more.

The remainder of the paper is organized as follows. In the next section we present the details of the field experiment. Section 3 presents the behavioral predictions. Our results are contained in section 4 , and section 5 concludes.

\section{DESIGN OF THE FIELD EXPERIMENT}

The study was performed in collaboration with a well-known, large charitable organization operating internationally. The aim of this organization is the support of children in need. Currently the organization is active in 38 countries and engaged in long-term development projects as well as in short-term emergency projects. A branch of this organization regularly sends out solicitation letters in the canton of Zurich (Switzerland). The organization has a list of roughly 10,000 addresses (mainly in the city of Zurich), to whom letters are addressed. This list is a so-called "warm" list, i.e., the general response rate to solicitations is relatively high.

A total of 9,846 solicitation letters were sent out in the "2001 Christmas mailing", almost all to private households ${ }^{1}$. The purpose of this mailing was to collect money for funding schools for street children in Dhaka (Bangladesh). The potential donors were informed about the details of the Dhaka project in the letters and asked to donate in its support. In addition to this letter, some people received either a "small" or a "large" gift. The small gift was one postcard plus envelope, while the large gift consisted of a set of four postcards with four envelopes. The postcards showed colored paintings drawn by children; an example is displayed in the Appendix. Those who received a gift (either small or large) were informed in a short remark at the very end of the letter that the postcards included are a "gift from the children from Dhaka", which "can be kept or given to others". The purpose of

\footnotetext{
${ }^{1}$ Only 22 of the 9.846 addresses belong to organizations and only one of these organizations actually donated (CHF 50). CHF $1 \sim 0.79$ US\$.
} 
this sentence was to assure people that the postcards are a gift for which nothing has to be paid, and to create a gift-exchange relation between the children (the potential receivers of the donation) and the donors. With the exception of this additional sentence, all solicitation letters were completely identical regardless of whether a gift was included or not. All letters were sent out on December 5, 2001.

Random selection determined whether a donor received a letter without a gift, with a small gift, or with a large one. Each address in the data base was randomly allocated a zero, a one or a two (with a random number generator). Those who had a zero were sent the letter without a gift, those with a one received a small gift and those with a two received a large gift. Our dependent variable is simply the donation decisions by the potential donors. These were routinely recorded by the organization.

\section{BEHAVIORAL HYPOTHESES}

In our field experiment two distinct behavioral motives may play an important role. The first is "warm glow", i.e., feelings of internal satisfaction that arise from helping people who are in need (Andreoni 1989, 1995). Warm glow is a behavioral disposition to donate unconditionally, i.e., without getting an extrinsic reward. The second potentially relevant motive is gift-exchange or reciprocity. Reciprocity means that "we are obligated to the future repayment of favors, gifts, invitations, and the like." (Cialdini 1992, p. 211, emphasis in the original). Reciprocity therefore describes a conditional behavior, e.g., donating as a response to receiving a gift ${ }^{2}$. The behavioral importance of reciprocity is well documented in many laboratory experiments (see, e.g., Fehr and Gächter 2000). A typical example is the study by Fehr, Kirchsteiger and Riedl (1993), which shows that trading partners can successfully establish a gift-exchange relation. By paying generous prices, buyers induce sellers to provide (costly) quality levels above the contractually enforceable level. In particular, the higher the price (the gift), the higher the average quality level. ${ }^{3}$

Applying the notions of warm glow and reciprocity to the present experiment yields the following behavioral predictions: People endowed with warm glow preferences donate

\footnotetext{
${ }^{2}$ A succinct description of reciprocity is given in the Edda, a $13^{\text {th }}$ century collection of Norse epic verses: "A man ought to be friend to his friend and repay gift with gift. People should meet smiles with smiles and lies with treachery."

3 These findings, which have recently been replicated in a "real" effort experiment (Gneezy 2003) support the corresponding efficiency wage argument put forward by Akerlof (1982).
} 
independent of whether they receive a gift or not. They should therefore donate in the no gift condition as well as in the two gift conditions. Reciprocally motivated subjects, on the other hand, donate because they feel obligated to the repayment of gifts. Thus they are expected to donate only in the two gift conditions. Since feelings of obligation should increase as the value of the included gift rises, more reciprocally motivated subjects should donate in the large compared to the small gift condition.

Thus in the no gift condition only warm glow is potentially relevant. This condition therefore informs us about the behavioral importance of the warm glow motive. In the two gift conditions, reciprocity is another possible motive in addition to feelings of warm glow. The difference between the gift conditions and the no gift condition therefore reveals the potential relevance of gift-exchange considerations ${ }^{4}$. Finally, since the value of the gifts is higher in the large compared to the small gift condition, the gift-exchange hypothesis predicts that we should observe more people donating in the large than in the small gift condition. These arguments can be summarized as follows:

GIFT-EXCHANGE HYPOTHESIS: The donation probability is lowest in the no gift condition, higher in the small gift condition and highest in the large gift condition.

\section{RESULTS}

In this section we first test the Gift-exchange hypothesis, i.e., whether including gifts increases the probability of donations. Second, we study whether gift-exchange considerations crowd in higher or lower donations, compared to the donations given for reasons of warm glow. Third, we address the question, whether the initiation of a giftexchange relation is profitable for the organization. To answer the latter question we compare the total amount of money donated in the three treatment conditions with the cost of providing the gifts. Since we have donation data covering the solicitation subsequent to the

\footnotetext{
${ }^{4}$ Note that an increase in donations between the no gift and the small gift condition could also be explained by a hypothesis that combines attention and warm glow. According to this hypothesis paying attention to the needs of others is a precondition for acting on altruistic preferences. The included postcard could raise attention and make it more likely for people to donate. Note, however, that this story cannot convincingly explain possible differences between the small and the large gift condition. It is unlikely that the attention arising from four postcards is much different than the attention arising from one.
} 
Christmas 2001 mailing, we can further check whether the observed increase in donations in the gift conditions is followed by lower donations in the subsequent mailing. This would be the case if donators intertemporally substitute.

\subsection{Does including a gift increase the frequency of donations?}

Table 1 presents the main results. It reports the donations that were given in the time period between December 5, 2001 and the end of February $2002^{5}$ under all three conditions (no gift, small gift, and large gift). The first row of Table 1 shows the absolute numbers of letters sent out in the three conditions. Rows two and three report the absolute and the relative number of people who donated under the three conditions. The results are striking. While the absolute number of people who donate under the no gift condition is 397 , this number increases to 465 in the small gift condition and to 691 in the large gift condition. In relative terms, the corresponding numbers are 12, 14 and 21 percent, respectively. Thus including a small gift increases the number of donors by 17 percent and including the large gift even increases the number of donors by as much as 75 percent. These results clearly support the Gift-exchange hypothesis.

TABLE 1: DONATION PATTERNS IN ALL TREATMENT CONDITIONS

\begin{tabular}{lccc}
\hline & No gift & Small gift & Large gift \\
\hline \hline Number of solicitation letters & 3,262 & 3,237 & 3,347 \\
Number of donations & 397 & 465 & 691 \\
Relative frequency of donations & 0.12 & 0.14 & 0.21
\end{tabular}

Table 2 shows that the observed treatment effects are statistically significant. We report a Probit regression in this table where the dependent variable is a dummy, which takes the value 1 if a person donated and zero otherwise ${ }^{6}$. This donation dummy is regressed on our treatment dummies. The variable "Small gift" is a dummy variable for the small gift

\footnotetext{
${ }^{5}$ We stopped collecting data at the end of February because first, there were essentially no further donations after the end of January and second, the next solicitation letter was sent out at the end of February (see section 4.3).

${ }^{6}$ All results are qualitatively the same if we use a linear probability model instead of a probit model.
} 
condition, while "Large gift" is a dummy variable for the large gift condition. Both coefficients are positive and significant at the 1-percent level. Further analysis also reveals that the increase in donations between the small gift and the large gift condition is also significant at the 1-percent level (Prob $\left.>\chi^{2}=.0000\right)$. This shows that including a gift in our set-up significantly increases the frequency of donations and that the more generous the gift, the higher the frequency.

TABLE 2: TREATMENT DIFFERENCES OF DONATION PROBABILITY

Dependent variable: Donation dummy

Small gift dummy

Large gift dummy

Constant

Number of observations

$$
\text { Prob }>\chi^{2}
$$

Pseudo $\mathrm{R}^{2}$
$0.102 * * *$

$0.348 * * *$

$-1.167 * * *$

$(0.028)$

9,846

0.000

0.011

Note: Probit regression with standard errors in parentheses. *** indicates significance at the 1-percent level. "Small gift" is a dummy variable taking the value 1 if the observation comes from the small gift condition and zero otherwise. Likewise, "Large gift" is a dummy variable, which takes the value 1 if the observation comes from the large gift condition and zero otherwise.

\subsection{Does gift-exchange crowd in higher or lower gifts?}

The results shown in Tables 1 and 2 support the gift-exchange hypothesis. The inclusion of gifts triggers feelings of obligation to repay the gift, which in turn crowd in donations that would otherwise not have been given. It is interesting to know whether these additional donations are qualitatively similar to those given under the no gift condition. Under the latter condition, feelings of warm glow are most likely the dominant motive for donating. Since the two motives, warm glow and feelings of obligation, are psychologically different, it might well be that they trigger different donation patterns as well. In particular, one might hypothesize that feelings of obligation crowd in rather low donations: If the only reason to 
donate is to get rid of a "bad conscience" a donor might choose a donation level which just compensates the organization for its expenditures. Since the material value of the postcards is rather low, donations might be low as well.

To address this issue Figure 1 shows a histogram of donations for all treatment conditions. The figure reveals that overall the distributions are similar. In all conditions 86 to 89 percent of the donations are below CHF 100 with peaks at values such as CHF 10, 20, 30, 50 or 100 . A closer inspection of the donation patterns shows, however, that there are some subtle differences. For low donations up to CHF 60, the cumulative frequency of donations is highest in the large gift condition (79 percent), followed by the small gift condition (74 percent) and the no gift condition (72 percent). Put differently, relatively low donations are more frequent under the large gift condition than the no gift condition. The opposite holds true for very high donations. This suggests that feelings of obligation may in fact crowd in relatively low gifts. To test this claim more directly, we performed two different distribution tests. The Kolmogorov-Smirnov test rejects that the donation distributions of the no gift and the large gift conditions are the same $(\mathrm{p}=.049)$. Comparing the other distributions yields no significant differences (no gift/small gift $\mathrm{p}=.262$; small gift/large gift $\mathrm{p}=.184$ ). These results are supported by the non-parametric Median test, which tests the null hypothesis that two samples are drawn from populations with the same median. Again, there is a significant difference between the no gift and the large gift condition $(p=.031)$ while the other distributions are not significantly different (no gift/small gift $\mathrm{p}=.532$; small gift/large gift $\mathrm{p}=.122$ ). Taken together the data suggest that at least some of the additionally made donations in the gift conditions are lower than those in the no gift condition. These differences are small, however. 


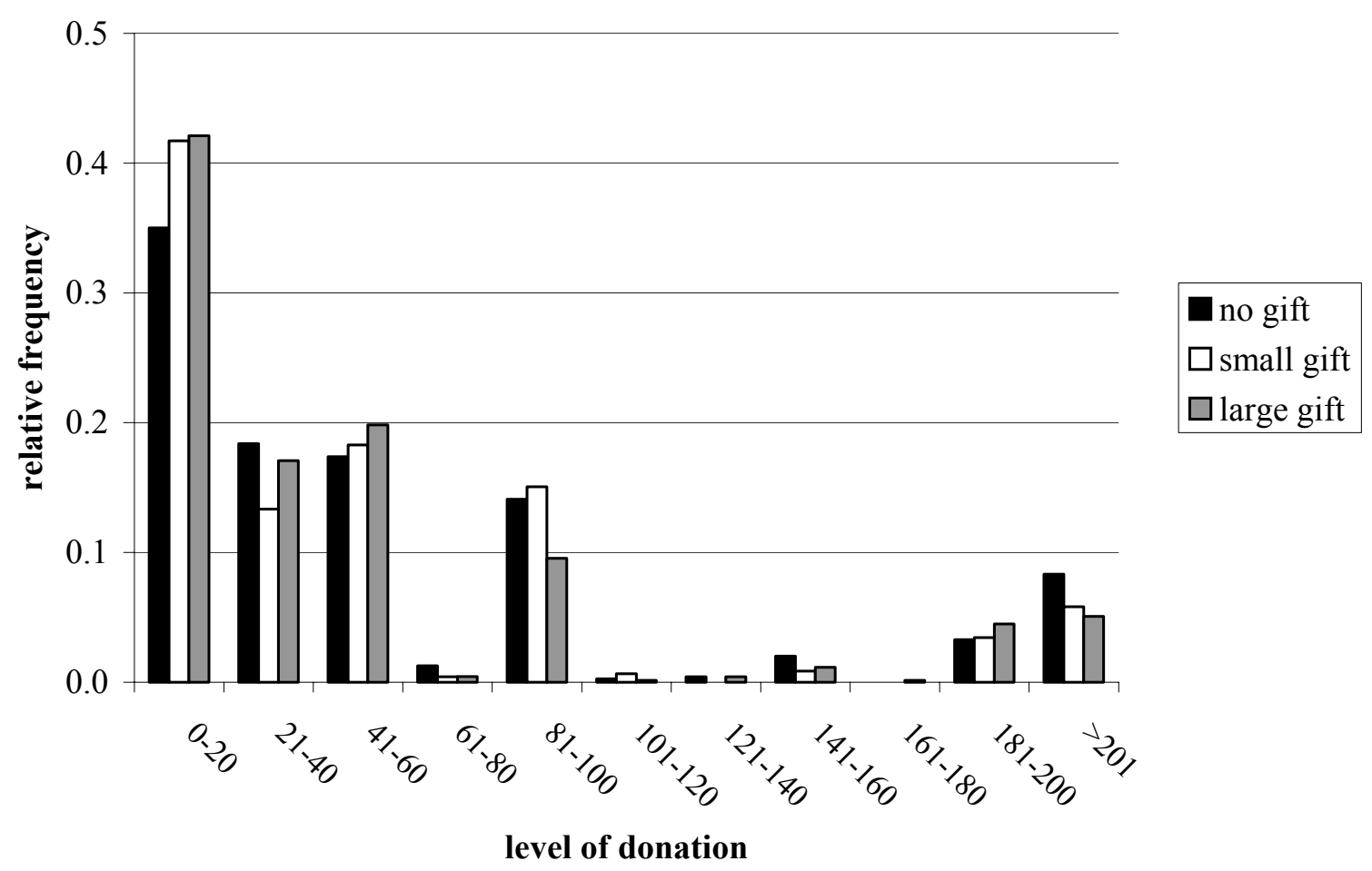

\subsection{Is the initiation of a gift-exchange profitable for the organization?}

From the charitable organization's perspective, the relevant question is whether including gifts is a profitable strategy. To answer this, we now examine the absolute amounts donated under each condition. In doing so, we restrict our analysis to all donations equal or below CHF 500. This excludes 39 donations (2.5 percent of all donations). These observations are excluded for two reasons. First, they completely blur the analysis of the absolute donation levels. To illustrate this, note that there was an extremely high donation of CHF 20,000 in the small gift condition, for example. Second, it seems rather unlikely that very high donations are affected by the treatment variations ${ }^{7}$.

Table 3 (first row) shows the absolute amount of money collected in the three treatment conditions. It amounts to CHF 24,673 in the no gift condition, CHF 27,106 in the small gift condition, and CHF 40,877 under the large gift condition. Thus as it holds for the relative frequency of donations (see Table 1), the sum of donations is lowest in the no gift

\footnotetext{
${ }^{7}$ Please note that there is nothing special about the cut off value of CHF 500. All results reported in this section are qualitatively the same if we consider a different cut off value, e.g., donations below CHF 600, CHF 400, CHF 300 etc.
} 
condition, higher in the low gift condition and highest in the large gift condition. The quantitative differences are quite substantial. There is a 66 percent increase from the no gift condition to the large gift condition, for example.

TABLE 3: ANALYSIS OF ABSOLUTE AMOUNTS OF DONATION AND POSSIBLE SUBSTITUTION EFFECTS

\begin{tabular}{lccc}
\hline \hline & No gift & Small gift & Large gift \\
\hline \hline Sum of donations Christmas 2001 mailing in CHF & 24,673 & 27,106 & 40,877 \\
Mean donation Christmas 2001 mailing in CHF & 7.56 & 8.37 & 12.21 \\
Sum of donations February 2002 mailing in CHF & 14,023 & 13,206 & 13,165 \\
Sum of Christmas and February mailing in CHF & 38,696 & 40,312 & 54,042 \\
\hline \hline
\end{tabular}

Note: All donations smaller or equal CHF 500

It is possible to calculate the organization's (potential) net benefits given these absolute numbers. Note first that total revenue across all three conditions was CHF 92,656. Simple extrapolation suggests that if no one had received a gift, revenue would have been much lower. If we take the average donation under the no gift condition (see Table 3, second row) and multiply it by the total number of letters sent out, we get a hypothetical amount of CHF 74,472. Since the cost of the postcards was roughly $\mathrm{CHF} 2,000^{8}$, the net gain of the manipulation amounts to CHF 16,184, an increase of about 22 percent. Of course revenues could have been even higher if everyone had received the large gift. In this case gross revenues would have been CHF 120,248 (average donation under the large gift condition as shown in the second row of Table 3, multiplied by the total number of letters). Subtracting CHF 4,800, which would have been the cost of sending a large gift (four postcards) to all potential donors, yields a net gain of CHF 40,976 or 55 percent when compared to the situation where no one receives a gift. Of course these numbers are hypothetical and should not be taken at face value. However, they indicate the potential benefits of establishing giftexchange relationships.

\footnotetext{
${ }^{8}$ This amount was actually donated by the University of Zurich.
} 
From the organization's point of view, one important question remains to be answered. So far we have shown that including gifts substantially increased donations in the Christmas 2001 mailing. However, it could be that the two gift treatments have an adverse effect on subsequent mailings. This would occur if donors intertemporally substitute their donations, i.e., if those donors who donated more in the Christmas 2001 mailing would donate less in the next mailing. In this case the organization would not necessarily benefit from sending out gifts. We can address this question because we have the donation data of the solicitation that followed the Christmas 2001 mailing. It took place at the end of February 2002. Its purpose was to collect money in support of poor mothers with little children. The list of addresses was the same as for the Christmas mailing.

If there is intertemporal substitution one would expect that the donation probability following the February 2002 mailing should be highest for the group of those donors who had not received a gift in the Christmas 2001 mailing, second highest for those who had been in the small gift condition and lowest for those who had received the large gift. In fact the donation probabilities are 9.6, 8.9 and 8.6 percent for the group of donors who had been in the no gift, the small gift and the large gift condition, respectively. Thus, the donation probabilities do vary in line with the intertemporal substitution argument. However, the differences are rather small, in particular if one compares these differences with the differences that occurred in the different treatments of the Christmas mailing. Moreover these differences are insignificant. This is shown by a simple Probit regression where we regress a donation dummy for the February 2002 mailing on our treatment dummies (exactly as in Table 2). The coefficients as well as the whole model are insignificant ( $p=0.353$ for the "Small gift" coefficient and $\mathrm{p}=0.126$ for the "large gift" coefficient; for the whole model Prob $\left.>\chi^{2}=0.3034\right)$.

As it holds with the donation probabilities, the absolute amount of money donated in the February 2002 mailing was highest in the no gift condition, followed by the small and the large gift conditions (see the third row of Table 3). Again, these differences are relatively small and insignificant. This is revealed by an OLS-regression, which regresses all donations of the February 2001 mailing on our treatment dummies ( $p=0.467$ for the "Small gift" coefficient and $\mathrm{p}=0.846$ for the "Large gift" coefficient; again the whole model is insignificant: Prob $>F=0.7563$ ). Table 3 (fourth row) also shows that if one adds the donations of the Christmas 2001 and the February 2002 mailings, the strong treatment 
effects of including gifts in the Christmas mailing persist. Taken together, it is possible that some intertemporal substitution occurs. However, this effect is quantitatively small and insignificant.

\section{CONCLUSION}

This paper has reported data from a field experiment on charitable giving. We studied three treatments, which were exogenous to the roughly 10,000 potential donors. In the first treatment the solicitation letter included no gift, in the second it included a small gift, and in the third it included a large gift. Our results convey a clear message. Including gifts gives rise to substantially different donation patterns. In the small gift condition the percentage of donations is 17 percent higher than in the no gift condition. In the large gift condition it is even 75 percent higher. Numbers are similar if we look at the absolute amounts that were donated.

The relevance of gift-exchange considerations shown in this paper may also help explaining the findings of List and Lucking-Reiley (2002). In their experiment, including seed money significantly raised donation rates. A possible explanation for this result is that subjects perceive seed money as a gift, which is reciprocated with higher donations, just as in our field experiment. This explanation is consistent in particular with the fact that donations in List and Lucking-Reiley (2002) seem to increase continuously in the level of seed money, a finding which is hard to reconcile with existing theories on charitable giving.

Given our results, it is tempting to conclude that the inclusion of gifts is a simple strategy for charitable organizations for collecting additional money. This conclusion, however, may be too optimistic. It is likely that the successful initiation of a gift-exchange relation depends on various and interacting factors. One important aspect concerns the nature of the gift and the message conveyed with it. If we had included gifts which were completely unrelated to the purpose of the solicitation or which were considered inappropriate, the response might have been weaker or even negative. Another question is whether a giftexchange relation can be repeatedly initiated. Surprise may be a key factor. Once donors get used to getting gifts, they might not feel obliged to their repayment anymore. More field experiments are needed to answer these questions. 


\section{REFERENCES}

Akerlof, G. (1982): “Labor Contracts as a Partial Gift Exchange”, Quarterly Journal of Economics 97, 543 - 569.

Andreoni, J. (1989): "Giving with Impure Altruism - Applications to Charity and Ricardian Equivalence", Journal of Political Economy 97, 1447-1458.

Andreoni, J. (1995): "Warm-Glow versus Cold-Prickle: The Effects of Positive and Negative Framing on Cooperation in Experiments", Quarterly Journal of Economics 110(1), 121.

Andreoni, J., Gale, W. and Scholz, J. (1996): "Charitable Contributions of Time and Money", Working paper, University of Wisconsin Madison.

Cialdini, R. B. (1992): "Social Motivations to Comply: Norms, Values, and Principles", in: Taxpayer Compliance, Vol. 2, 200-227, ed. by J. A. Roth and J. T. Scholz, University of Pennsylvania Press, Philadelphia.

Fehr, E., Kirchsteiger, G. and Riedl, A. (1993): "Does Fairness prevent Market Clearing? An Experimental Investigation", Quarterly Journal of Economics 108, 437-460.

Fehr, E. and Gächter, S. (2000): "Fairness and Retaliation - The Economics of Reciprocity", Journal of Economic Perspectives 14, 159-181.

Frey, B. S. and Meier, S. (2003): "Who Cares about the Pro-social Behavior of Others? Testing 'Conditional Cooperation' in a Field Experiment”, Working paper, University of Zurich.

Gneezy, U. (2003): "Do High Wages Lead to High Profits? An Experimental Study of Reciprocity Using Real Effort”, Working paper, University of Chicago, GSB 2003.

List, J. A. and Lucking-Reiley, D. (2002): "The Effects of Seed Money and Refunds on Charitable Giving: Experimental Evidence from a University Capital Campaign", Journal of Political Economy 110, 215-233. 
Appendix: An example of the included postcards

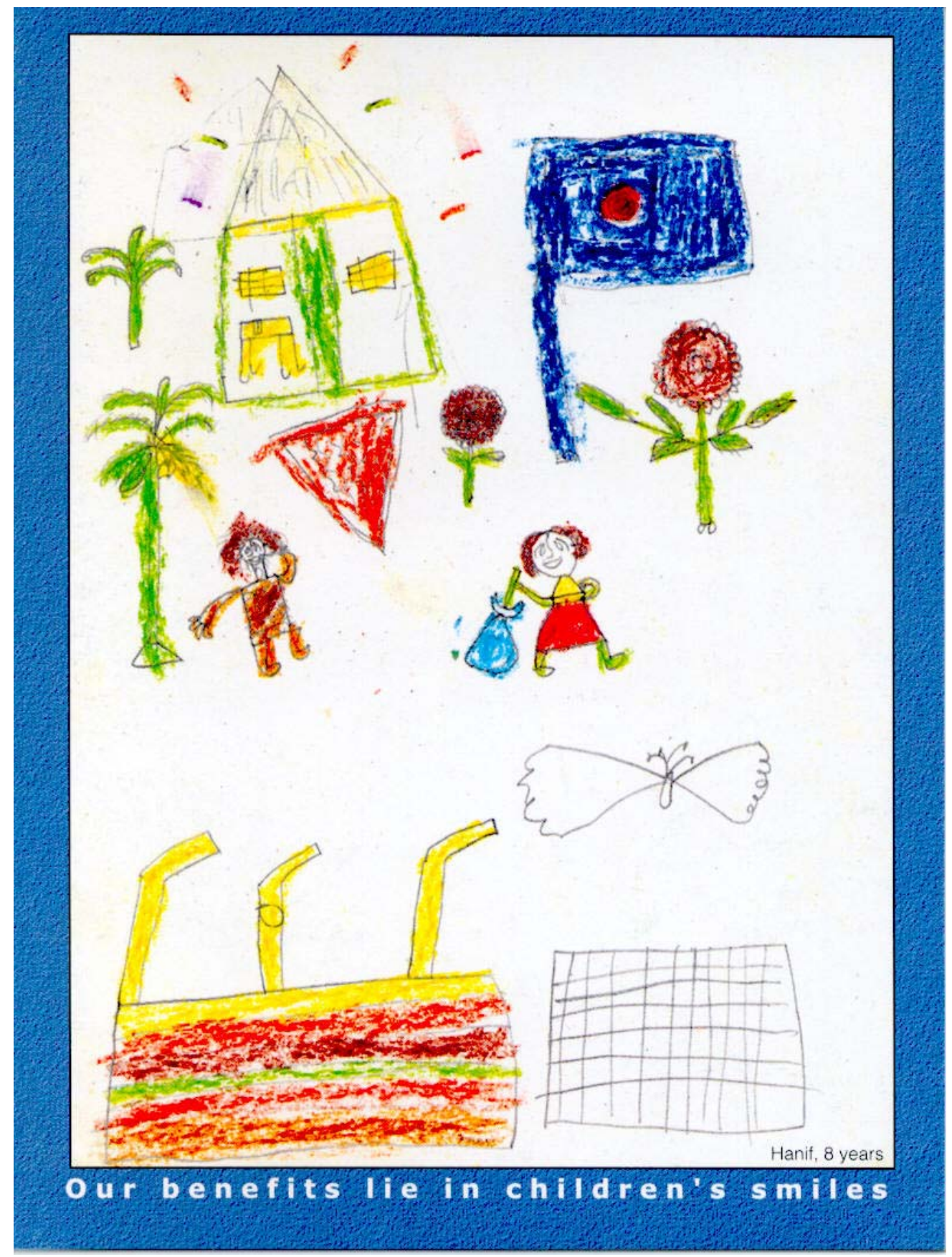

